\title{
Effect of pH on dissociation of casein micelles in yak skim milk
}

\author{
M. Yang, ${ }^{* 1}$ G. D. Zhang, $†$ J. T. Yang, ${ }^{*}$ D. Sun, † P. C. Wen, † and W. B. Zhang† \\ ${ }^{*}$ College of Science, and \\ †College of Food Science and Engineering, Gansu Agricultural University, Lanzhou, China 730070
}

\begin{abstract}
The dissociation of yak casein $(\mathrm{CN})$ micelles was evaluated by scanning electron microscopy, particle size, fluorescence properties, and soluble mineral and CN molecule content at $\mathrm{pH} 4.6$ to 8.2. The results showed that the size of $\mathrm{CN}$ micelles remained constant with decreasing $\mathrm{pH}$ from 8.2 to 5.8 but sharply increased at $\mathrm{pH}$ $\leq 5.4$. Casein micelles began to aggregate at $\mathrm{pH} 5.4$, and the serum magnesium, potassium, iron, zinc, copper, and manganese levels had their minimum values at this pH level. During acidification, colloidal calcium phosphate dramatically disassociated from yak $\mathrm{CN}$ micelles, but the soluble CN monomer content decreased slightly. During alkalization, the soluble calcium and phosphorus content decreased below $\mathrm{pH} 6.8$ but increased with $\mathrm{pH}$ increases from 6.8 to 8.2. However, the soluble CN content increased markedly during alkalization. The emission wavelength of 8-anilino-1-naphthalenesulfonic acid sodium salt fluorescence decreased during both acidification and alkalization from $\mathrm{pH}$ 6.6, whereas the opposite was found for intrinsic fluorescence.
\end{abstract}

Key words: yak milk, casein micelle, mineral, fluorescence property

\section{INTRODUCTION}

Yak milk is a unique kind of milk with high protein and mineral contents, and it is particularly rich in $\alpha_{\mathrm{S2}^{-}}$ CN (4.80 and $2.68 \mathrm{~g} / \mathrm{L}$ in yak and bovine milk, respectively), $\beta$-CN (18.20 and $9.60 \mathrm{~g} / \mathrm{L}$ in yak and bovine milk, respectively), calcium (198-227 mg/100 g of yak milk; $114 \mathrm{mg} / 100 \mathrm{~g}$ of bovine milk), and phosphorus (154-170 mg/100 g of yak milk; $103 \mathrm{mg} / 100 \mathrm{~g}$ of bovine milk; Li et al., 2010; Yang et al., 2014a; Cui et al., 2016). It is also a crucial material for herdsmen on the Qinghai-Tibet Plateau. Several yak milk products are manufactured, such as $\mathrm{CN}$, yogurt, and milk powder.

Received August 9, 2017.

Accepted November 26, 2017.

${ }^{1}$ Corresponding author: yummy12@163.com
Yak CN has higher emulsifying activity, foam stability, foaming capacity, and water absorption than cow CN, but its emulsion stability is much lower than that of cow CN (Yang et al., 2014a). Yak CN and caseinate are the major products made from qula, which is a yak milk product made by a traditional method: defatting, acidifying, and drying in air (Liu et al., 2013). Qula contains approximately $80 \%$ protein, and it is much easier to collect, store, and transport than fresh yak milk because of the remote location and poor transportation on the Qinghai-Tibet Plateau. As an important industrial material, qula is melted in water with $\mathrm{pH} 8$ to 10 and then acidified by hydrochloric acid to $\mathrm{pH} 4.6$ to extract the $\mathrm{CN}$ products. However, the processing of qula is crude due to a lack of knowledge about the effects of $\mathrm{pH}$ on yak milk, resulting in low yields and poor functional properties of the products.

It is well known that $\mathrm{pH}$, as well as heat treatment, can alter the microstructure and physicochemical behavior of CN micelles significantly (Liu and Guo, 2008). Therefore, much research has been undertaken on the effect of $\mathrm{pH}$ on bovine milk, combined with heating. It has been shown that $\mathrm{CN}$ micelles transform from a loose to a compact microstructure during acidification (Liu and Guo, 2008; Liu et al., 2017). At pH <5.4, the formation of $\mathrm{CN}$ aggregates with complex behavior occurs, followed by milk gel formation at pH 4.8 (McMahon et al., 2009; Anema and Li, 2015). It has further been demonstrated that bovine $\mathrm{CN}$ particle size has a significant negative correlation with $\mathrm{pH}$ (Taterka and Castillo, 2015).

Colloidal calcium phosphate (CCP) contributes to the conformation and stability of $\mathrm{CN}$ micelles (de Kruif et al., 2012). The trend of change in CN micelles throughout acidification can be estimated from the distribution of calcium and phosphorus between serum and the micellar phase. During acidification, the micellar contents of colloidal calcium, phosphorus, and magnesium decrease, whereas those of sodium and potassium first decrease and then increase sharply around pH 5.8 or 5.5 (Law and Leaver, 1998; Silva et al., 2013; Liu et al., 2017). Meanwhile, the micellar CN molecule content changes slightly with decreasing $\mathrm{pH}$ (Anema and Klostermeyer, 1997; Law and Leaver, 1998). 
Although there are many reports of the influence of $\mathrm{pH}$ on bovine milk, it is doubtful whether their results could be applied to yak milk processing and whether yak milk is deviating from the general knowledge on bovine CN micelles because of the great differences between yak and bovine milk in terms of their constituents and properties (Wang et al., 2013; Yang et al., 2014a,b). Previous studies on the influence of $\mathrm{pH}$ on characteristics of yak milk have proven that the heat stability of yak milk protein reaches a maximum at approximately $\mathrm{pH} 6.8$, that heating leads to a marked increase in serum $\kappa$-CN content, and that particle size decreases with increases in $\mathrm{pH}$, with similar, though less marked, changes in $\alpha-\mathrm{CN}$ and $\beta-\mathrm{CN}$ ( $\mathrm{Li}$ et al., 2014; Wang et al., 2017). The dissociation degree of $\alpha-\mathrm{CN}, \beta-\mathrm{CN}$, and $\kappa-\mathrm{CN}$ in heating bovine milk with different temperature has the lowest value under $\mathrm{pH}$ 6.5. According to a report of qula's properties across a large $\mathrm{pH}$ range, its solubility dramatically increases as the $\mathrm{pH}$ increases from 6.0 to 8.0 and decreases as the $\mathrm{pH}$ increases from 9.0 to 12.0 , but the solubility of yak CN changes little as the $\mathrm{pH}$ increases from 6.0 to 12.0 (Liu et al., 2013; Yang et al., 2014a). However, there is no report of the microstructure and dissociation of CCP and other minerals from yak $\mathrm{CN}$ micelles at different $\mathrm{pH}$ levels. Moreover, the dissociation of $\mathrm{CN}$ molecules and minerals across a wide $\mathrm{pH}$ range without heating has not been discussed in detail.

In this study, the dissociation of yak $\mathrm{CN}$ monomers and 8 minerals was measured at $\mathrm{pH} 4.6$ to 8.2. The microstructure and fluorescence properties of yak $\mathrm{CN}$ micelles at $\mathrm{pH} 5.0$ to 8.2 are presented, and the relationship between soluble calcium and phosphorus increases in supernatant and yak CN micellar size is analyzed. The aim of this study was to provide basic data and reference information for industrial processing and manufacture of qula and yak milk products.

\section{MATERIALS AND METHODS}

\section{Materials}

Yak milk was collected from Zhuaxixiulong Town of the Tianzhu grassland, on the Qinghai-Tibetan Plateau, in northwest China. The Tianzhu grassland is a typical pasturing area for yak production. After milking, $0.02 \%$ (wt/vol) sodium azide was added to the milk to inhibit bacterial growth. Yak milk was then placed in sterile plastic bottles and stored in a box filled with ice, which was transported to the laboratory within $6 \mathrm{~h}$. Yak milk was defatted twice by centrifugation (TDD5M, Changsha Pingfan Instrument Co. Ltd., Changsha, China) at $4,000 \times g$ for $10 \mathrm{~min}$ at $20^{\circ} \mathrm{C}$ (Yang et al., 2015).

\section{pH Adjustment}

Raw skim yak milk samples $(50 \mathrm{~mL})$ were $\mathrm{pH}$ adjusted from $4.60 \pm 0.02$ to $8.20 \pm 0.02$ using 0.1 to 1 $M \mathrm{NaOH}$ or 0.1 to $1 \mathrm{M} \mathrm{HCl}$ at intervals of 0.4 . The samples were allowed to equilibrate for at least $2 \mathrm{~h}$, and minor readjustments were made to achieve a stable $\mathrm{pH}$.

\section{Particle Size Measurement}

Sample aliquots of $50 \mu \mathrm{L}$ were diluted with distilled water to $15 \mathrm{~mL}$ for particle size measurement. The average diameter of particles was determined using a Malvern Zetasizer (Malvern Instruments Ltd., Malvern, $\mathrm{UK}$ ) at $25^{\circ} \mathrm{C}$ (Chandrapala et al., 2012).

\section{Scanning Electron Microscopy}

Samples were diluted and dropped onto silicon chips. The silicon chips were freeze-dried for $24 \mathrm{~h}$ using a vacuum freeze-drying machine (GLZ-0.4, $\mathrm{Su}$ Yuan Zhong Tian Scientific Inc., Beijing, China), then coated with gold. Images of typical structures were recorded at a magnification of 20,000 using an S-4800 microscope (Hitachi Ltd., Tokyo, Japan) operating at $5 \mathrm{kV}$.

\section{Fluorescence Spectroscopy}

Skim milk samples $(1.5 \mathrm{~mL})$ were diluted to $5 \mathrm{~mL}$ with distilled water for fluorescence measurements. Intrinsic fluorescence experiments were performed with an RF-5301PC luminescence spectrometer (Japan Shimadzu Co., Kyoto, Japan) for solutions in a 1-cm path length quartz cell at room temperature $\left(20-24^{\circ} \mathrm{C}\right)$. The excitation and emission slits were fixed at $5 \mathrm{~nm}$, the excitation wavelength was set at $280 \mathrm{~nm}$, and the emission spectra were collected from 290 to $450 \mathrm{~nm}$.

A volume of $200 \mu \mathrm{L}$ of 8-anilino-1-naphthalenesulfonic acid sodium salt $\left(\mathbf{A N S} ; 8.0 \times 10^{-3} M\right)$ was mixed with $8 \mathrm{~mL}$ of diluted milk and allowed to stand for 3 min. The excitation and emission slits were fixed at 5 $\mathrm{nm}$, the excitation wavelength was set at $390 \mathrm{~nm}$, and the emission spectra were collected from 400 to $650 \mathrm{~nm}$ (Yang et al., 2015).

\section{Protein Analysis of Supernatant}

To separate protein aggregates and $\mathrm{CN}$ micelles, acidified skim milk was centrifuged at $120,000 \times g$ for 40 min at $20^{\circ} \mathrm{C}$ using a Beckman Optima XL-100K refrigerating ultracentrifuge (Beckman Coulter, Brea, CA). The supernatant was collected for analysis of protein and mineral contents. Supernatant $(4 \mathrm{~mL})$ was 
added to $4 \mathrm{~mL}$ of buffer solution $(8 \mathrm{~mol} / \mathrm{L}$ of urea, 165 $\mathrm{mmol} / \mathrm{L}$ of Tris, $44 \mathrm{mmol} / \mathrm{L}$ of sodium citrate, and $0.3 \%$ (vol/vol) $\beta$-mercaptoethanol). Protein standards (20 mg) were separately dissolved in $10 \mathrm{~mL}$ of buffer solution as above.

The protein content of the supernatant was measured by reversed-phase HPLC apparatus (Agilent 1100; Agilent Technologies, Santa Clara, CA) equipped with a C18 column $(150 \mathrm{~mm} \times 4.6 \mathrm{~mm}, 300-\AA$ pores, $5-\mu \mathrm{m}$ particles; Agilent) and a UV/visible detector at 220 $\mathrm{nm}$. Solvents A and B were solutions of acetonitrilewater-trifluoroacetic acid of different ratios (100:900:1 and 900:100:1 by volume, respectively). After filtering through a $0.45-\mu \mathrm{m}$ filter (Membrana, Wuppertal, Germany), $20 \mu \mathrm{L}$ samples were analyzed.

The analysis was carried out by applying a binary gradient profile of the mobile phase. The gradient elution program was run at a constant flow rate of 1.0 $\mathrm{mL} / \mathrm{min}$ and was set as follows: 0- to 13-min linear gradient from 20 to $31.3 \% \mathrm{~B}$, followed by a 3-min isocratic elution of $31.3 \% \mathrm{~B}$; 17- to 19-min linear gradient from 31.3 to $34.7 \% \mathrm{~B}$, followed by a 3 -min isocratic elution of $34.7 \% \mathrm{~B}$; 23- to 24 -min linear gradient from 34.7 to $36.0 \% \mathrm{~B}$, followed by a 5 -min isocratic elution of $36.0 \%$ B; 30 - to 31-min linear gradient from 36.0 to $38.2 \%$ $\mathrm{B}$, followed by a 5 -min isocratic elution of $38.2 \% \mathrm{~B}$; 37 - to 38 -min linear gradient from 38.2 to $40.8 \% \mathrm{~B}$; and 39 - to 45 -min linear gradient from 40.8 to $46.0 \% \mathrm{~B}$. The temperature of the column was maintained at $25^{\circ} \mathrm{C}$.

\section{Mineral Analysis of Supernatant}

The supernatants were hydrolyzed by hydrogen peroxide and nitric acid. The calcium, magnesium, phosphorus, and potassium contents were determined using an Optima 7000DV inductively coupled plasma optical emission spectrometer (Perkin Elmer, Waltham, MA). The iron content was determined by a GGX-800 atomic absorption spectrometer (Haiguang Instrument Ltd. Co., Beijing, China). The manganese, copper, and zinc contents were measured by an ICPQc inductively coupled plasma mass spectrometer (Thermo Fisher, Waltham, MA).

\section{Statistical Analysis}

All data were expressed as mean \pm standard deviation from at least 3 independent trials. The differences were assessed by 1-way ANOVA and Duncan's multiple range tests. Statistical significance was set at $P$ $<0.05$. The data were analyzed using PASW Statistics 18.0 software (SPSS Inc., Chicago, IL) and Origin 8.0 (OriginLab Corporation, Northampton, MA).

\section{RESULTS AND DISCUSSION}

\section{Effect of pH on Particle Size of Yak Skim Milk}

The Z-average diameter of skim milk at different $\mathrm{pH}$ values is shown in Figure 1. The $\mathrm{CN}$ micelles reached a maximum size at $\mathrm{pH}$ 5.0, which was close to the isoelectric point of $\mathrm{CN}$. The size of $\mathrm{CN}$ micelles in yak skim milk at $\mathrm{pH} 5.4$ was $144 \mathrm{~nm}$ smaller than at $\mathrm{pH}$ 5.0. A sharp increase in particle size indicated the beginning of the aggregation phase of $\mathrm{CN}$ at $\mathrm{pH} \leq 5.4$, which has been identified in the milk of different species (Moitzi et al., 1996; Jaubert et al., 1999; Liu et al., 2017). Higher polydispersity index and multimodal size distribution were observed at the same $\mathrm{pH}$ in bovine skim milk (Liu et al., 2017). As shown in Figure 1, pH had no effect on the $\mathrm{Z}$-average diameter of $\mathrm{CN}$ micelles in the $\mathrm{pH}$ range 5.8 to 8.2. It has been reported that the size of yak CN micelles was in the range of 193 to $212 \mathrm{~nm}$ at natural pH levels (Wang et al., 2013; Li et al., 2014; Yang et al., 2014b). However, a size of $149.9 \pm 0.2 \mathrm{~nm}$ at $\mathrm{pH}$ 6.6 was observed in the present study, possibly due to the use of different measurement techniques and the sourcing of yak milk from a different geographical area.

The steady particle size was found when increasing $\mathrm{pH}$ from 5.8 to 8.2 (Figure 1), and other researchers have found an almost constant particle size in yak skim milk when increasing $\mathrm{pH}$ over the range of 6.4 to 7.6 (Li et al., 2014). Therefore, it could be deduced that $\mathrm{pH}$ does not significantly influence the size of CN micelles in yak skim milk over the $\mathrm{pH}$ range of 5.8 to 8.2 . The

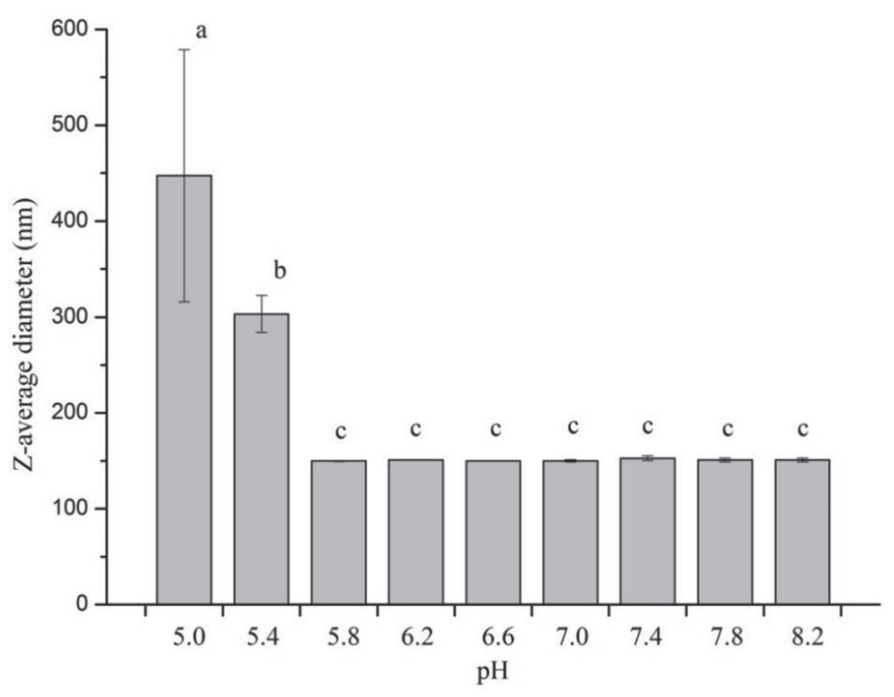

Figure 1. Z-average diameter of yak skim milk at different $\mathrm{pH}$ levels. Different letters $(\mathrm{a}-\mathrm{c})$ indicate significant differences $(P<0.05)$ between samples. Means \pm SD from at least triplicate analyses are given. 
same conclusion has been deduced in cow skim milk from $\mathrm{pH} 5.4$ to 6.7 (Liu et al., 2017).

Generally, the Z-average diameter of $\mathrm{CN}$ micelles is a complex colloidal property. The change of $\mathrm{CN}$ micellar structure might be determined by a combination of size and various structural parameters whose relative contributions would change during acidification and alkalization (Liu et al., 2017). Therefore, the topography, fluorescence properties, and dissociation of $\mathrm{CN}$ molecules and minerals from $\mathrm{CN}$ micelles were measured to reveal the structural change of $\mathrm{CN}$ micelles during acidification and alkalization.

\section{Topography of CN Micelles in Yak Skim Milk at Different pH Levels}

The topography of yak CN micelles, obtained by scanning electron microscopy, at different $\mathrm{pH}$ levels proved that the size of the micelles changed little with increasing $\mathrm{pH}$ from 5.8 to 8.2 (Figure 2). During acidification, micelles seemed to maintain their integrity until the $\mathrm{pH}$ decreased below 5.4 (Figure 2B, C, D). Scanning electron microscopy indicated that CN micelles came closer to each other and aggregated before clusters with a network microstructure were formed at $\mathrm{pH} 5.0$ (Figure 2A). Although there was no obvious aggregation at $\mathrm{pH} 5.4$, the stretched structure of the micelles became denser and small units of aggregates appeared (Figure 2B).

According to scanning electron microscopy images, the aggregation of yak $\mathrm{CN}$ micelles with acidification could be divided into 3 stages. The first stage was at $\mathrm{pH} 6.6$ to 5.8, when the micelles maintained their original shape and individual characteristics, although there were a few micelles connected to each other, which could be due to the high micelle content and the particles not being dispersed very well. With continuous acidification to around $\mathrm{pH} 5.4$, the second stage, a few $\mathrm{CN}$ micelles formed small aggregates but most retained their individuality, consistent with the Z-average diameter results. It seemed that significant aggregation occurred at $\mathrm{pH} 5.0$ (the beginning of the third stage), when micelles lost their individual shape and linked to each other, thus achieving the network microstructure. This observation was consistent with the results by Gonzalez-Jordan et al. (2015), who found a sharp increase in density and the formation of large flocs at $\mathrm{pH} 5.0$ in bovine milk by confocal laser scanning microscopy. Compared with the initial aggregation $\mathrm{pH}$ of yak CN micelles of 5.4, that of bovine $\mathrm{CN}$ micelles was reported to be 5.8 (Gastaldi et al., 1996). Therefore, yak CN micelles are more stable than bovine $\mathrm{CN}$ micelles because of their higher calcium and phosphorus contents.
During alkalization, yak CN micelles appeared to retain their shape and individuality (Figure 2E, F, G, H). It also seemed that some small micelles became smaller still due to the slight dissociation of $\mathrm{CN}$ molecules, whereas larger particles changed little with increasing $\mathrm{pH}$ from 7.0 to 8.2. Moreover, the size of $\mathrm{CN}$ micelles decreased slightly throughout alkalization according to scanning electron microscopy, contrary to the Z-average size values (Figure 1). Although the size of aqueous CN micelles remained stable with $\mathrm{pH}$ change, the interaction among $\mathrm{CN}$ molecules in micelles was changed; the CN micelles shrank to a smaller size during dry treatment for scanning electron microscopy.

\section{Fluorescence Spectroscopy of Yak Skim Milk at Different pH Levels}

The tyrosine, tryptophan, and phenylalanine residues of protein usually fluoresce. The fluorescence spectrum of protein is sensitive to the microenvironment because of these chromophores. According to Figure 3A, the intrinsic fluorescence spectrum of yak skim milk changed with $\mathrm{pH}$ alteration. Figure 3B showed the maximum intrinsic fluorescence intensity $\left(\boldsymbol{I}_{f}\right)$ and its emission wavelength $(\lambda \max )$ in yak skim milk at different $\mathrm{pH}$ values. It showed that the $I_{f}$ increased sharply when $\mathrm{pH}$ decreased from 6.6 to 5.0. During alkalization, $I_{f}$ decreased at $\mathrm{pH}$ 7.0, then slightly increased with increasing $\mathrm{pH}$. The $I_{f}$ values at $\mathrm{pH}<6.6$ were much higher than those at $\mathrm{pH}>6.6$. The $\lambda \max$ of intrinsic fluorescence increased both when $\mathrm{pH}$ increased from 6.6 to 8.2 and when it decreased from 6.6 to 5.8 . When $\mathrm{pH}$ decreased at $\mathrm{pH} \leq 5.8, \lambda \max$ remained constant.

With acidification, the protonation of AA led to stronger hydrogen bonds between CN micelles. In addition, cation $-\pi$ interaction occurred between the cationic and aromatic side chains of $\mathrm{CN}$ (Liu and Guo, 2008). Therefore, the structure of CN micelles became more compact, resulting in tryptophan residues being buried in a hydrophobic domain and the $I_{f}$ increasing. Although $\lambda \max$ increased at the beginning of acidification, the increase was less than $2 \mathrm{~nm}$. During alkalization, deprotonation of the carboxylic groups created a loose CN micellar structure, which led to the dissociation of $\mathrm{CN}$ from micelles. Thus, the content of soluble $\mathrm{CN}$ increased, and a red shift of $\lambda \max$ and increase of $I_{f}$ were observed (except for at $\mathrm{pH}$ 7.0).

In terms of the ANS fluorescence spectrum of yak skim milk at different $\mathrm{pH}$ levels, $\lambda$ max presented an opposite trend to that of intrinsic fluorescence, which decreased during both acidification and alkalization from the natural $\mathrm{pH}$ of 6.6 (shown in Figure 3C). The trend of $I_{f}$ in the ANS fluorescence spectrum was similar to that of intrinsic fluorescence (shown in Figure 3D). 


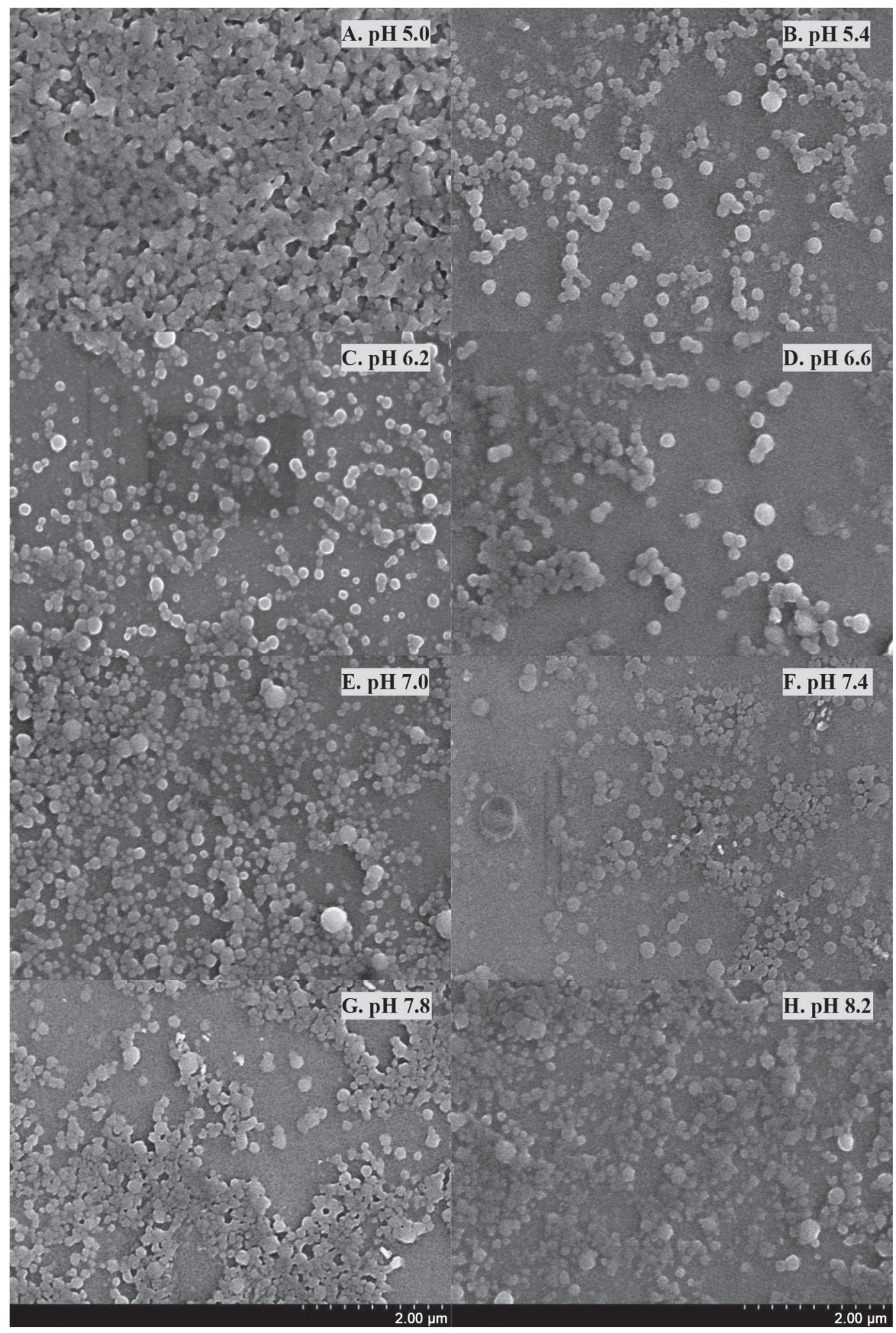

Figure 2. The topography of CN micelles in yak skim milk at different pH levels (scanning electron microscope; $\times 20,000$ ). 
A. Intrinsic fluorescence emission spectra

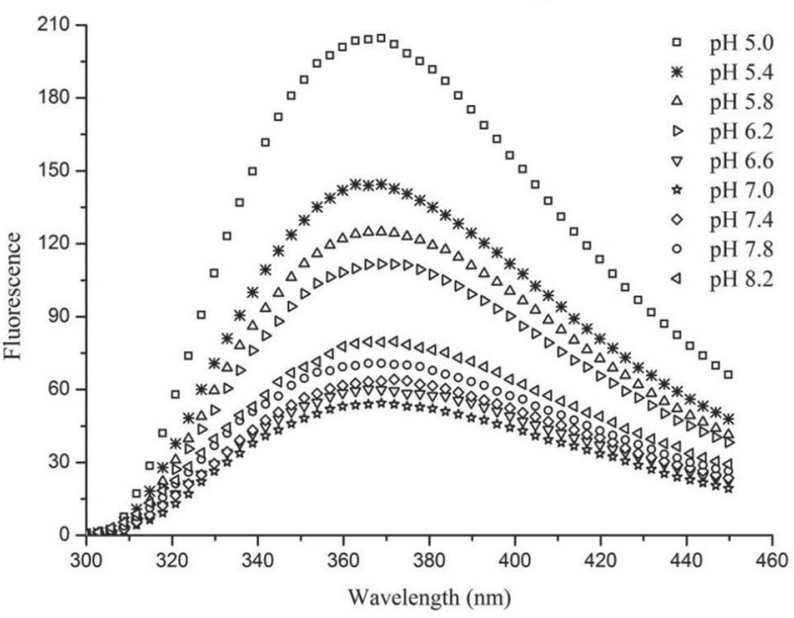

B. $I_{f}$ and $\lambda \max$ of intrinsic fluorescence

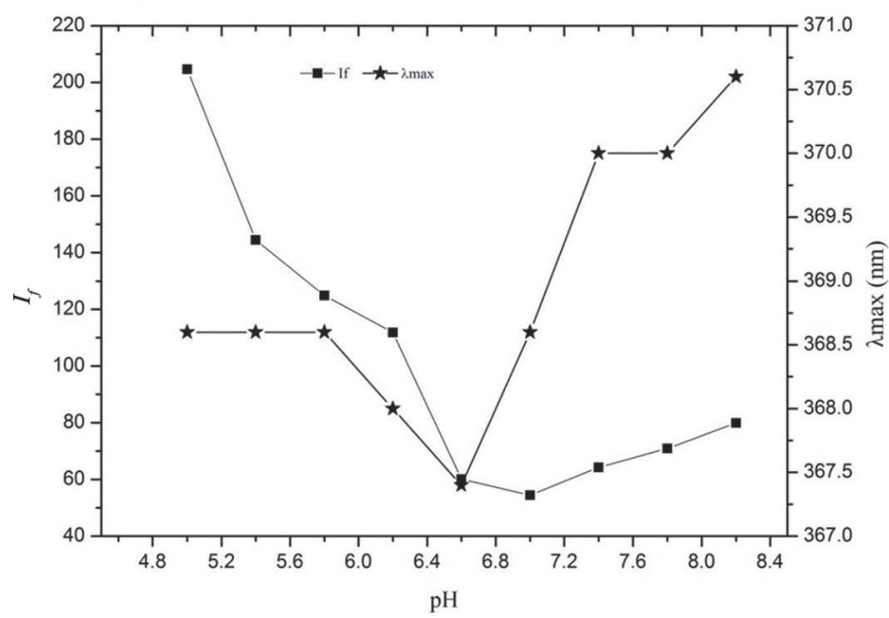

C. ANS fluorescence emission spectra

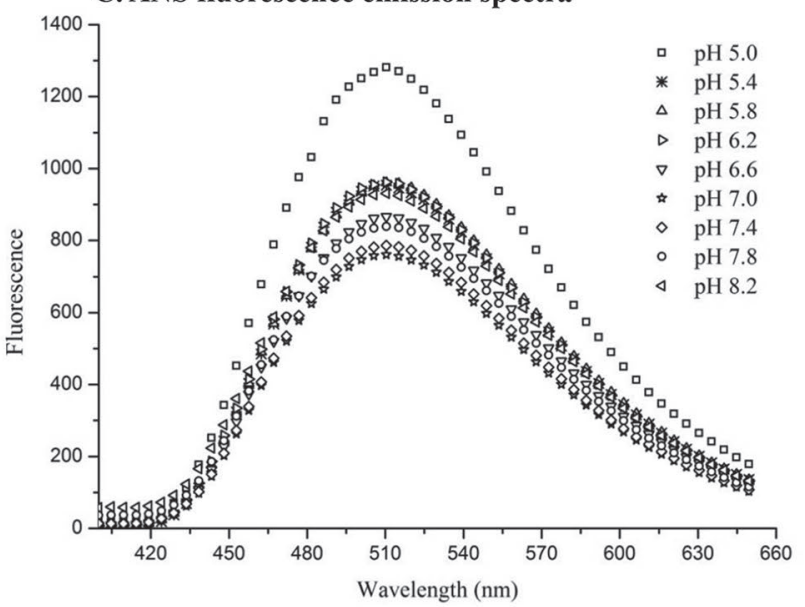

D. I $I_{f}$ and $\lambda \max$ of ANS fluorescence.

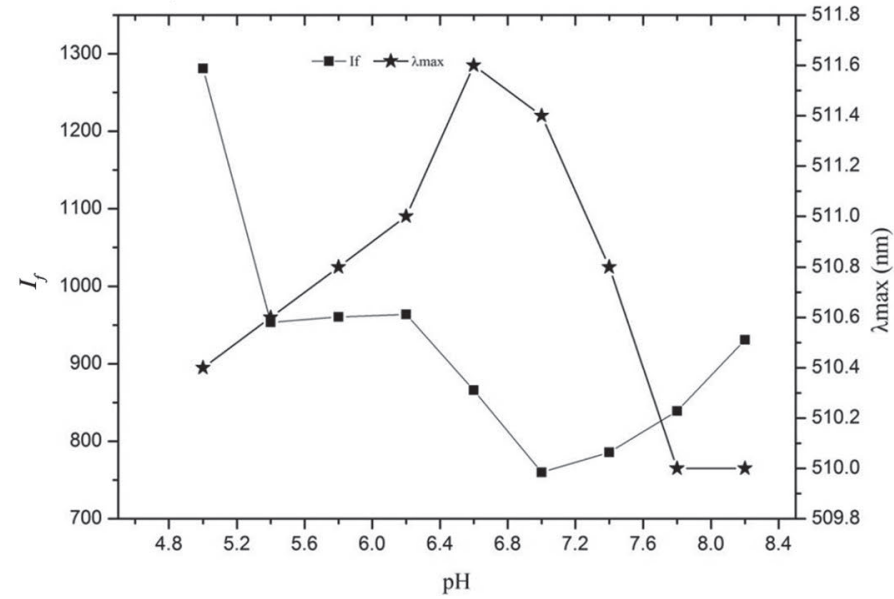

Figure 3. Intrinsic and 8-anilino-1-naphthalenesulfonic acid sodium salt (ANS) fluorescence emission properties of yak skim milk at different $\mathrm{pH}$ levels. (A) Intrinsic fluorescence emission spectra. (B) Fluorescence intensity $\left(I_{f}\right)$ and emission wavelength $(\lambda \max )$ of intrinsic fluorescence. (C) ANS fluorescence emission spectra. (D) $I_{f}$ and $\lambda \max$ of ANS fluorescence.

The ANS anion bound readily to the cationic groups of lysine, arginine, and histidine side chains. During acidification, the negative charge decreased and ANS binding to $\mathrm{CN}$ increased; thus, $I_{f}$ increased. In addition, acidification changed the structure of $\mathrm{CN}$ micelles (as intrinsic fluorescence showed), and the surface hydrophobicity of yak CN micelles increased. The blue shift of $\lambda \max$ with acidification could be attributed to compaction of the $\mathrm{CN}$ micelle structure. With alkalization, the dissociation of minerals and $\mathrm{CN}$ molecules weakened the steric hindrance between ANS and $\mathrm{CN}$, which could lead to an increase of $I_{f}$. Moreover, the change of whey-CN interaction and the slight disruption of CN micelles would make the hydrophobicity of yak $\mathrm{CN}$ micelles increased during alkalization (Chandrapala et al., 2013). However, the state transformation of phosphate and the addition of sodium made the internal structure of micelles more compact; thus, $\lambda \max$ shifted toward the lower wavelength. A different ANS fluorescence spectrum trend was found in bovine $\mathrm{CN}$ micelles (Liu and Guo, 2008). It could be concluded that minerals and whey protein have a significant effect on both intrinsic and ANS fluorescence spectra of milk.

\section{Effect of $\mathrm{pH}$ on Dissociation of Protein from CN Micelles in Yak Skim Milk}

The degree of protein dissociation in yak skim milk supernatant against $\mathrm{pH}$ is presented in Figure 4 by means of protein concentration. The $\mathrm{k}$-CN concentration decreased with acidification from $\mathrm{pH} 6.6$ to 5.0, as did the $\beta-\mathrm{CN}$ concentration. The content of $\alpha-\mathrm{CN}$ es- 
sentially changed little from $\mathrm{pH} 5.0$ to 6.6 except for at $\mathrm{pH}$ 5.8. The slight decreases in $\kappa-\mathrm{CN}$ and $\beta-\mathrm{CN}$ content during acidification implied that they had isoelectrically aggregated. In other words, the $\mathrm{CN}$ molecule did not dissociate from the micelle during acidification. Law and Leaver (1998) reported that the extent of dissociation of the $\mathrm{CN}$, especially $\mathrm{k}-\mathrm{CN}$, increased significantly as cow skim milk was acidified between $\mathrm{pH} 6.7$ and 5.5 at $20^{\circ} \mathrm{C}$. The higher stability of yak $\mathrm{CN}$ micelles should be due to their higher content of CCP compared with cow CN micelles (Wang et al., 2013).

Whey protein followed a different trend from the CN, with its content increasing when $\mathrm{pH}$ decreased from 6.6 to 5.8 and then decreasing. The content of the $3 \mathrm{CN}$ in skim milk, especially $\beta-\mathrm{CN}$, increased dramatically with alkalization from $\mathrm{pH} 6.6$ to 8.2. However, the whey protein content remained constant throughout alkalization.

The $\alpha$-CN content followed a $\mathrm{pH}$-independent profile during acidification, attributed to its higher level of phosphorylation and lower isoelectric point compared with other CN molecules (McMahon et al., 2009). The marked increase in $\mathrm{CN}$ content throughout $\mathrm{pH}$ increase from 6.6 to 8.2 indicated the dissociation of $\mathrm{CN}$ micelles. It has been reported that $\kappa-\mathrm{CN}$ content in yak skim milk supernatant increased slightly across the $\mathrm{pH}$ ranges 6.4 to 7.6 ( $\mathrm{Li}$ et al., 2014), 6.6 to 7.4 (Xu et al., 2015), and 6.0 to 7.0 (Wang et al., 2017). The pH had no effect on the whey protein content of yak skim milk supernatant in the $\mathrm{pH}$ range 6.6 to 8.4. The trend of whey protein content observed in the present study was similar to that in other analyses of yak skim milk ( $\mathrm{Li}$

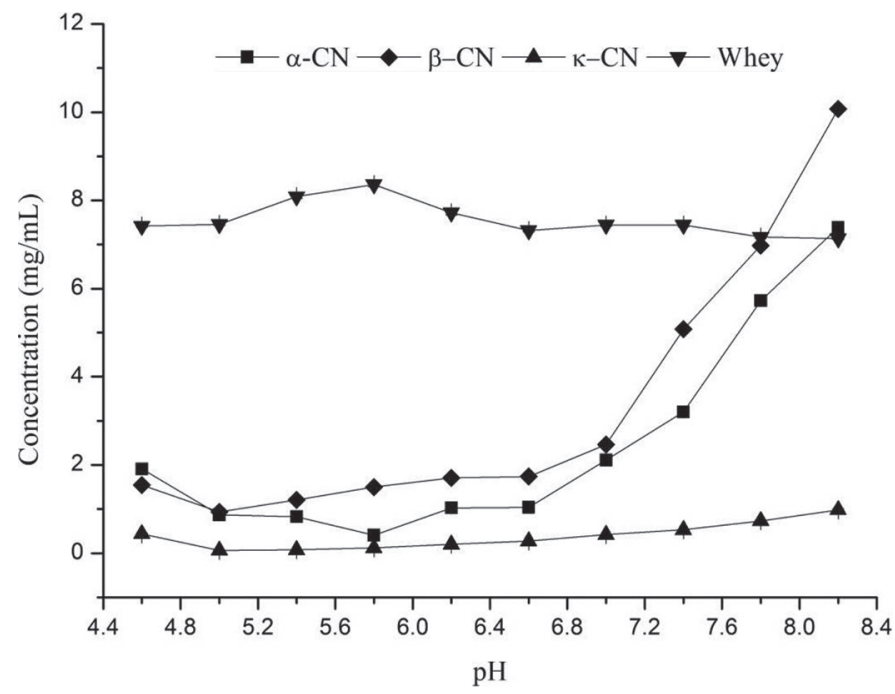

Figure 4. Concentration of yak $\mathrm{CN}$ monomers and whey protein in serum phase at different $\mathrm{pH}$ levels. et al., 2014; Xu et al., 2015; Wang et al., 2017). The soluble protein content in the milk of other species has been widely reported, and the soluble protein components identified in yak skim milk in the present study are comparable with those previously reported (Anema and Klostermeyer, 1997; Anema et al., 2007; Pesic et al., 2014; Anema and Li, 2015; Liu et al., 2017).

It was likely that $\beta$-CN had a higher concentration because of its higher content in skim milk and lower level of phosphorylation. Although the $\mathrm{k}$-CN content of skim milk was much lower than that of $\alpha-$ and $\beta-C N$, its content was slightly lower than that of $\alpha-\mathrm{CN}$ at $\mathrm{pH}$ 5.8 to 7.4 because $\kappa$ - $\mathrm{CN}$ had the lowest phosphorylation and was located on the surface of $\mathrm{CN}$ micelles. Therefore, the order of preferential dissociation from CN micelles was $\kappa>\beta>\alpha$, which correlated with their levels of phosphorylation.

\section{Effect of $\mathrm{pH}$ on Dissociation of Minerals in Yak Skim Milk at Different pH Levels}

Calcium and phosphorus are the main and most important minerals in milk. Two-thirds of calcium and one-third of phosphorus are in the micellar phase, presenting as CCP or micellar calcium phosphate (de Kruif et al., 2012). Casein molecules link together by bridging CCP to form CN micelles (Mata et al., 2011). Calcium was released from $\mathrm{CN}$ micelles rapidly $(P<$ 0.05 ) when $\mathrm{pH}$ decreased from 6.6 to 4.6 (shown in Figure 5A). Additionally, the phosphorus content increased throughout acidification. It was shown that the soluble calcium and phosphorus contents reached a maximum at $\mathrm{pH} 4.6$ and a minimum at $\mathrm{pH} 6.8$ and then increased with increasing $\mathrm{pH}$. The calcium and phosphorus contents in serum at $\mathrm{pH} 8.2$ were similar to those at $\mathrm{pH}$ 5.4.

Sharp increases in soluble calcium and phosphorus in the serum of skim milk acidified with $\mathrm{HCl}$ were observed between $\mathrm{pH} 6.0$ and 4.6 in most previous works (Gastaldi et al., 1996; Gonzalez-Jordan et al., 2015; Koutina and Skibsted, 2015; Liu et al., 2017), suggesting increased solubilization of CCP. Organic and inorganic phosphates are protonated during acidification of milk, while, simultaneously, the serum phase is no longer saturated with calcium phosphate, thus leading to the gradual solubilization of CCP until a new steady state is achieved. A different result reported by Law and Leaver (1998) indicated that acidification with $\mathrm{HCl}$ did not markedly affect the solubilization of $\mathrm{CCP}$ in bovine skim milk over most of the $\mathrm{pH}$ range 6.7 to 4.6 , which was measured immediately and after re-equilibration for $18 \mathrm{~h}$ at $4^{\circ} \mathrm{C}$ and $22^{\circ} \mathrm{C}$ after acidification to preset $\mathrm{pH}$ values (Law and Leaver, 1998; Zhao 
and Corredig, 2016). It is possible that the response of mineral systems to acidification is time dependent (Liu et al., 2017).

The calcium and phosphorus contents in yak skim milk supernatant decreased in the $\mathrm{pH}$ range 6.6 to 7.0 and then increased as the $\mathrm{pH}$ range increased from 7.0 to 8.2 , which was consistent with results obtained for cow milk and similar to those for buffalo milk with a turning point of $\mathrm{pH} 7.8$ (Ahmad et al., 2009).

With $\mathrm{pH}$ increase, inorganic phosphorus changes from $\mathrm{HPO}_{4}{ }^{2-}$ toward $\mathrm{PO}_{4}{ }^{3-}$. The $\mathrm{PO}_{4}{ }^{3-}$ state has a greater affinity for calcium $\left(2.88 \times 10^{6} \mathrm{M}^{-1}\right)$ than does $\mathrm{HPO}_{4}{ }^{2-}\left(642 M^{-1}\right.$; Ahmad et al., 2009). As the calcium phosphate in the aqueous phase of the milk was satu-
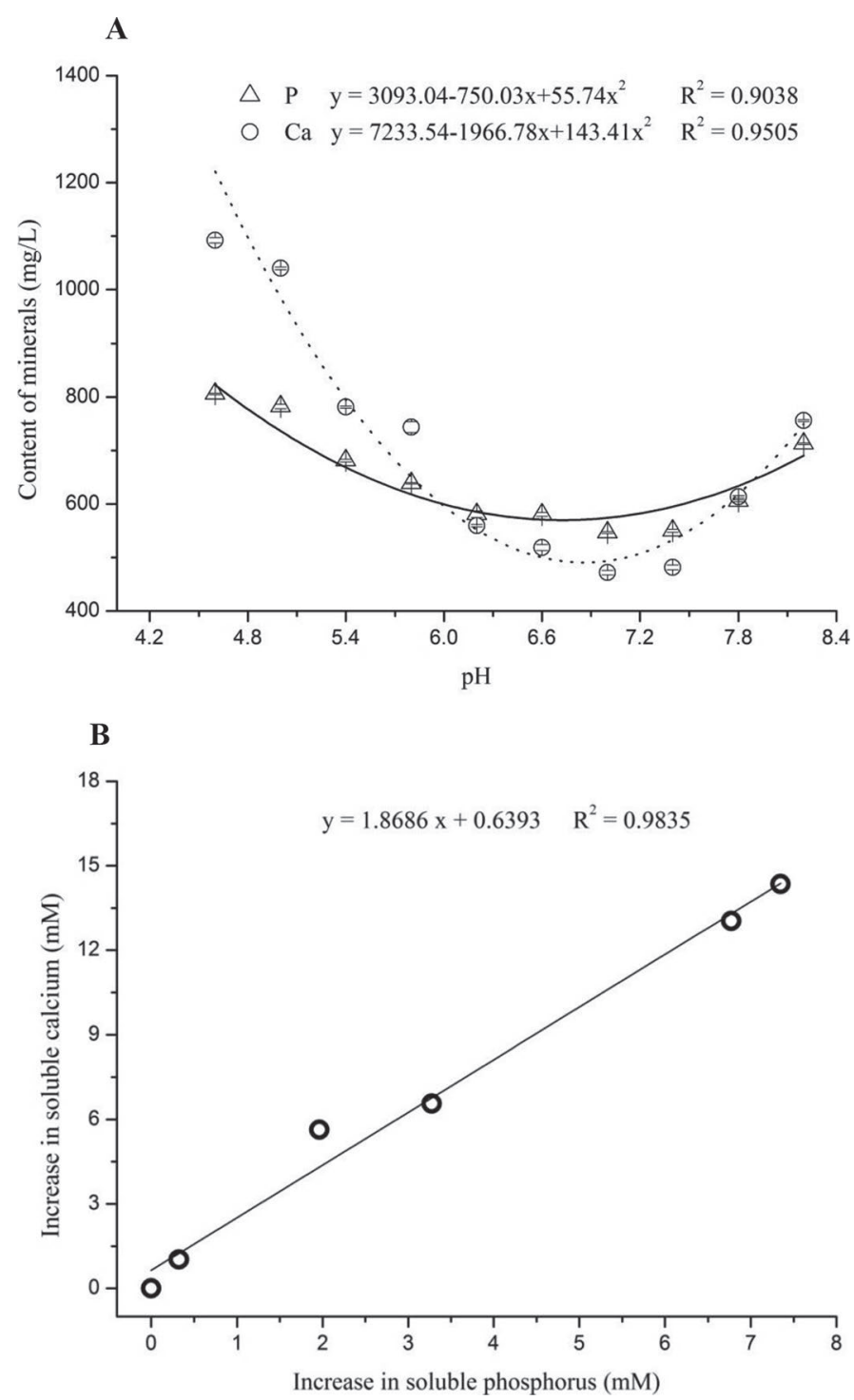

Figure 5. (A) Calcium and phosphorus content of yak skim milk supernatant. (B) Profile of increase in calcium versus phosphorus in yak skim milk supernatant. rated, precipitates of this salt formed. Thus, the calcium and phosphorus contents decreased. However, this precipitate was too light to remove by ultracentrifugation, but it was small enough to associate with proteins that would contain nucleation points or incorporate into micellar calcium (Ahmad et al., 2009). A considerable amount of sodium was added to the skim milk during continuous alkalization. The addition of sodium was likely to have affected the electrostatic interaction among $\mathrm{CN}$ micelles, as seen with the addition of $\mathrm{NaCl}$ in the literature (Huppertz and Fox, 2006; Nguyen et al., 2017). Sodium replaced some calcium bound to CN micelles via phosphoseryl residues, thus increasing the calcium content in the supernatant. In addition, the dissociation of $\mathrm{CN}$ micelles (shown in Figure 3) caused CCP dissolution, resulting in increases in soluble calcium and phosphorus.

The calcium and phosphorus contents of supernatant followed a polynomial function for $\mathrm{pH}$ values of 4.6 to 8.2 (Figure 5A). A linear relationship between increases in soluble calcium and phosphorus in yak skim milk at $\mathrm{pH} 4.6$ to 6.6 was identified, and its function was shown in Figure 5B, which was consistent with previous findings for bovine milk at pH 4.9 to 6.7 (Liu et al., 2017). The molar ratios between colloidal calcium and inorganic phosphorus of bovine milk were reported to be in the range of 1.7 to 1.9 (Silva et al., 2013). The molar ratio of 1.87 in yak milk indicated the same basic type of CCP as was found in bovine milk.

The magnesium, potassium, iron, zinc, copper, and manganese contents in supernatant and in yak skim milk are presented in Table 1. During acidification, the levels of most minerals in serum first increased and then sharply decreased at $\mathrm{pH} 5.4$, followed by further increase. In other words, all minerals reached their minimum content at $\mathrm{pH}$ 5.4. Scanning electron microscopy has shown that small yak $\mathrm{CN}$ micelle aggregates formed at $\mathrm{pH} 5.4$, which should be presumed to absorb the minerals and were precipitated by ultracentrifugation. In addition, a compact microstructure and elastic properties of bovine $\mathrm{CN}$ micelles were found at $\mathrm{pH} 5.5$, and the loss tangent and viscosity reached a minimum at approximately $\mathrm{pH} 5.3$ according to rheology (Gastaldi et al., 1996; Liu and Guo, 2008). Casein micelles are hypothesized to pass through a transition state to compensate for the loss of interaction with CCP not only by new protein-protein interactions but also by electrostatic interactions between minerals and AA residues. This is the most likely reason for the minimum mineral levels observed in yak milk supernatant at $\mathrm{pH}$ 5.4.

During alkalization, the mineral content first decreased and then markedly increased $(P<0.05)$. The increasing number of negative AA residues strongly associated with cations during alkalization, thus decreas- 
Table 1. Total and soluble mineral content of yak skim milk at different $\mathrm{pH}$ levels

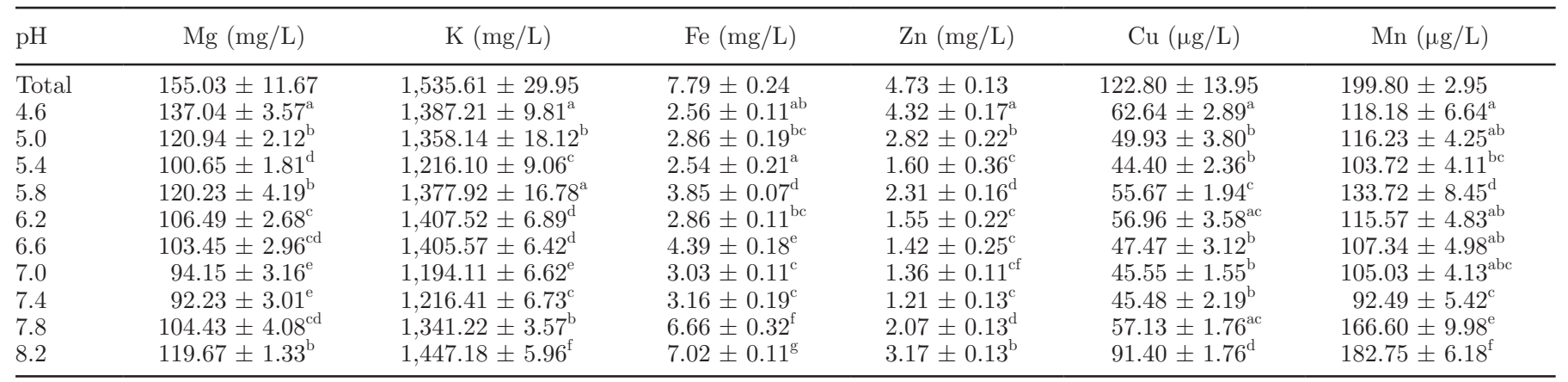

${ }^{\mathrm{a}-\mathrm{g}}$ Means within a column with different superscripts differ $(P<0.05)$.

ing the mineral content of the supernatant at the beginning of alkalization. However, the soluble CN molecules continuously increased in number with increasing $\mathrm{pH}$ and were left in supernatant containing minerals, so mineral content again increased.

\section{CONCLUSIONS}

During acidification, CCP dramatically disassociated from yak $\mathrm{CN}$ micelles, and the $\mathrm{CN}$ monomers contents of the supernatant decreased gradually, though the size of $\mathrm{CN}$ micelles changed little before the $\mathrm{pH}$ reached 5.4. A linear relationship between soluble calcium and phosphorus increases in acidified yak milk was found, similar to bovine milk. Whey protein content in the supernatant first increased and then decreased, in contrast to the trends of the CN. According to scanning electron microscopy, yak CN micelles passed through 3 stages during acidification. In first stage at $\mathrm{pH} 6.6$ to 5.8, micelles retained individuality, but $\lambda \max$ of intrinsic fluorescence increased while that of ANS fluorescence decreased. In the second stage, with $\mathrm{pH}$ around 5.4, a few small aggregations formed and the Z-average size increased greatly, whereas the contents of magnesium, potassium, iron, zinc, copper, and manganese in serum had their minimum values. During the third stage, at $\mathrm{pH} \leq 5.0$, a network microstructure of $\mathrm{CN}$ aggregation was achieved, with a significant increase in size and soluble mineral content. The higher $\mathrm{pH}$ value at which yak CN aggregation occurs compared with that for bovine milk may be due to the higher calcium and phosphorus contents in yak milk. With regard to the ANS fluorescence spectrum of yak skim milk, $\lambda \max$ decreased throughout acidification. The size of yak CN micelles remained constant throughout alkalization, but the soluble calcium and phosphorus contents decreased before $\mathrm{pH} 6.8$ due to transition of the phosphorus state and then increased with increasing $\mathrm{pH}$ from 6.8 to 8.2. However, the soluble CN content increased markedly during alkalization due to dissociation of $\mathrm{CN}$ micelles.
The whey protein content of the supernatant remained almost constant throughout alkalization. Minimum levels of other minerals were reached in the $\mathrm{pH}$ range of 7.0 to 7.4, and they increased with persistent dissociation of $\mathrm{CN}$ micelles during $\mathrm{pH}$ increase. With alkalization, $\lambda \max$ of ANS fluorescence decreased, whereas that of intrinsic fluorescence increased. The $I_{f}$ of both ANS and intrinsic fluorescence spectra increased with both $\mathrm{pH}$ decrease and increase from 6.6. Compared with bovine milk, yak milk has greater $\mathrm{pH}$ stability due to its higher calcium and phosphorus contents.

\section{ACKNOWLEDGMENTS}

This work was financially supported by the National Natural Science Foundation of China (no. 31560430; Beijing, China), the Fuxi Fostering Foundation of Gansu Agricultural University (no. Gaufx-02J02; Lanzhou, China), and the China Postdoctoral Science Foundation (no. 2015M572611; Beijing, China).

\section{REFERENCES}

Ahmad, S., M. Piot, F. Rousseau, J. F. Grongnet, and F. Gaucheron. 2009. Physico-chemical changes in casein micelles of buffalo and cow milks as a function of alkalinisation. Dairy Sci. Technol. 89:387-403.

Anema, S. G., and H. Klostermeyer. 1997. Heat-induced, pH-dependent dissociation of casein micelles on heating reconstituted skim milk at temperatures below $100^{\circ}$ C. J. Agric. Food Chem. 45:11081115 .

Anema, S. G., S. K. Lee, and H. Klostermeyer. 2007. Effect of pH at heat treatment on the hydrolysis of $\kappa$-casein and the gelation of skim milk by chymosin. Lebensm. Wiss. Technol. 40:99-106.

Anema, S. G., and Y. Li. 2015. Reassociation of dissociated caseins upon acidification of heated pH-adjusted skim milk. Food Chem. 174:339-347.

Chandrapala, J., G. J. Martin, B. Zisu, S. E. Kentish, and M. Ashokkumar. 2012. The effect of ultrasound on casein micelle integrity. J. Dairy Sci. 95:6882-6890.

Chandrapala, J., B. Zisu, S. Kentish, and M. Ashokkumar. 2013. Influence of ultrasound on chemically induced gelation of micellar casein systems. J. Dairy Res. 80:138-143.

Cui, G. X., F. Yuan, A. A. Degen, S. M. Liu, J. W. Zhou, Z. H. Shang, L. M. Ding, J. D. Mi, X. H. Wei, and R. J. Long. 2016. Composi- 
tion of the milk of yaks raised at different altitudes on the Qinghai-Tibetan Plateau. Int. Dairy J. 59:29-35.

de Kruif, C. G., T. Huppertz, V. S. Urban, and A. V. Petukhov. 2012. Casein micelles and their internal structure. Adv. Colloid Interface Sci. 171-172:36-52.

Gastaldi, E., A. Lagaude, and B. T. D. L. Fuente. 1996. Micellar transition state in casein between $\mathrm{pH} 5.5$ and 5.0. J. Food Sci. 61:59-64.

Gonzalez-Jordan, A., P. Thomar, T. Nicolai, and J. Dittmer. 2015. The effect of $\mathrm{pH}$ on the structure and phosphate mobility of casein micelles in aqueous solution. Food Hydrocoll. 51:88-94.

Huppertz, T., and P. F. Fox. 2006. Effect of $\mathrm{NaCl}$ on some physicochemical properties of concentrated bovine milk. Int. Dairy J. 16:1142-1148.

Jaubert, A., C. Durier, A. Kobilinsky, and P. Martin. 1999. Structural organization of the goat casein micelle: Effect of the physico-chemical environment ( $\mathrm{pH}$, temperature, ionic strength) on its mineral and protein composition. Int. Dairy J. 9:369-370.

Koutina, G., and L. H. Skibsted. 2015. Calcium and phosphorus equilibria during acidification of skim milk at elevated temperature. Int. Dairy J. 45:1-7.

Law, A. J. R., and J. Leaver. 1998. Effects of acidification and storage of milk on dissociation of bovine casein micelles. J. Agric. Food Chem. 46:5008-5016.

Li, H., Y. Ma, A. J. Dong, J. Q. Wang, Q. M. Li, S. H. He, and M. Jean-Louis. 2010. Protein composition of yak milk. Dairy Sci. Technol. 90:111-117.

Li, Q., Y. Ma, S. He, W. Elfalleh, W. Xu, J. Wang, and L. Qiu. 2014. Effect of $\mathrm{pH}$ on heat stability of yak milk protein. Int. Dairy J. 35:102-105.

Liu, D., Y. Yu, J. Zhang, X. Liu, M. Wang, Y. Hemar, J. M. Regenstein, and P. Zhou. 2017. Biochemical and physico-chemical changes of skim milk during acidification with glucono- $\delta$-lactone and hydrogen chloride. Food Hydrocoll. 66:99-109.

Liu, H. N., C. Zhang, H. Zhang, H. Y. Guo, P. J. Wang, Y. B. Zhu, and F. Z. Ren. 2013. pH treatment as an effective tool to select the functional and structural properties of yak milk caseins. J. Dairy Sci. 96:5494-5500.

Liu, Y., and R. Guo. 2008. pH-dependent structures and properties of casein micelles. Biophys. Chem. 136:67-73.

Mata, J. P., P. Udabage, and E. P. Gilbert. 2011. Structure of casein micelles in milk protein concentrate powders via small angle X-ray scattering. Soft Matter 7:3837-3843.
McMahon, D. J., H. Du, W. R. McManus, and K. M. Larsen. 2009 Microstructural changes in casein supramolecules during acidification of skim milk. J. Dairy Sci. 92:5854-5867.

Moitzi, C., A. Menzel, P. Schurtenberger, and A. Stradner. 1996. The $\mathrm{pH}$ induced sol-gel transition in skim milk. J. Food Sci. 61:59-64.

Nguyen, B. T., C. Chassenieux, T. Nicolai, and C. Schmitt. 2017. Effect of the $\mathrm{pH}$ and $\mathrm{NaCl}$ on the microstructure and rheology of mixtures of whey protein isolate and casein micelles upon heating. Food Hydrocoll. 70:114-122.

Pesic, M. B., M. B. Barac, S. P. Stanojevic, and M. M. Vrvic. 2014. Effect of $\mathrm{pH}$ on heat-induced casein-whey protein interactions: A comparison between caprine milk and bovine milk. Int. Dairy J. $39: 178-183$.

Silva, N. N., M. Piot, A. F. de Carvalho, F. Violleau, A. L. Fameau, and F. Gaucheron. 2013. pH-induced demineralization of casein micelles modifies their physico-chemical and foaming properties. Food Hydrocoll. 32:322-330.

Taterka, H., and M. Castillo. 2015. The effect of whey protein denaturation on light backscatter and particle size of the casein micelle as a function of $\mathrm{pH}$ and heat-treatment temperature. Int. Dairy J. 48:53-59

Wang, L., Y. Ma, J. Cui, S. A. Oyeyinka, J. Cheng, and S. He. 2017. Yak milk whey protein denaturation and casein micelle disaggregation/aggregation at different $\mathrm{pH}$ and temperature. Int. Dairy J. 71:131-135.

Wang, P., H. Liu, P. Wen, H. Zhang, H. Guo, and F. Ren. 2013. The composition, size and hydration of yak casein micelles. Int. Dairy J. 31:107-110.

Xu, W., S. He, Y. Ma, Y. Zhang, Q. Li, L. Wang, and R. Wang. 2015. Effect of $\mathrm{pH}$ on the formation of serum heat-induced protein aggregates in heated yak milk. Int. J. Dairy Technol. 68:342-348.

Yang, M., N. Cui, Y. Fang, Y. Shi, J. Yang, and J. Wang. 2015. Influence of succinylation on the conformation of yak casein micelles. Food Chem. 179:246-252.

Yang, M., Y. Shi, P. Wang, H. Liu, P. Wen, and F. Ren. 2014a. Effect of succinylation on the functional properties of yak caseins: A comparison with cow caseins. Dairy Sci. Technol. 94:359-372.

Yang, M., W. Zhang, P. Wen, Y. Zhang, and Q. Liang. 2014b. Heat stability of yak micellar casein as affected by heat treatment temperature and duration. Dairy Sci. Technol. 94:469-481.

Zhao, Z., and M. Corredig. 2016. Short communication: Serum composition of milk subjected to re-equilibration by dialysis at different temperatures, after pH adjustments. J. Dairy Sci. 99:2588-2593. 